\section{Building}

$\mathrm{T}$ HE staff of the Building Research Station now numbers 150 , and the results of their work for the past year are embodied in the report* of the Building Research Board for 1933. The work carried out has been very comprehensive, including the investigation of the weathering of building stones, building material of all kinds, the structure and strength of these materials, and the efficiency of buildings from the point of view of the user. The ever-growing volume of special investigations and inquiry work-more than 1,500 inquiries were dealt with during the year-indicates that the activities of the Building Research Station are becoming increasingly known, and that the facilities offered are coming into regular demand.

A considerable amount of work has been carried out on Portland and Clipsham stones, and work on sandstone is in progress. It is found that measure. ments of 'microporosity' (a measure of the porosity of the oolitic grains-sée 1931 report) and 'saturation coefficient' (a measure of the degree of saturation reached under standardised conditions of soaking) form a reasonably certain basis for the expression of an opinion on the quality of any particular sample of Portland stone of the normal type. Tests on the Clipsham stone have led to the conclusion that the more shelly type is of superior weathering quality. The crushing strength of stones is found to be a quality quite independent of their resistance to weathering.

* Department of Scientific and Industrial Research : Report of the Building Research Board, with the Report of the Director of Building Research for the year 1933. Pp. $x+139$. (London: H.M. Stationery Office, 1934.) $28.6 d$. net.

\section{Research}

Work on stone preservatives shows that the effective life of certain of the materials commonly employed is limited to about 12-18 months.

Many investigations on bricks are described. Research was carried out to discover the amount of soluble salts a brick may safely be allowed to contain. It is stated that a brick containing 0.1 per cent of water-soluble magnesium sulphate would almost certainly cause failure in plaster applied to it; but an equal amount of calcium sulphate would be quite innocuous.

The behaviour of bricks depends greatly on their texture. Examinations of bricks from different regions of a kiln showed serious underfiring in some of these regions. A systematic firing of different clays under different conditions of temperature and kiln atmosphere is now progressing. The behaviour of the various bricks was examined by exposing them in a 'cemetery', the bricks being partly buried in soil. The results effectively dispose of the idea that high crushing strength denotes great resistance to exposure.

Many other investigations are described dealing with the thermal expansion of glass, paints, cement and concrete, the effect of sea-water on concrete, the effect of moisture content on the thermal resistance of fibre board, asphalt roofing, the supposed effects of different types of heat radiation on health, etc., all of which are of great scientific interest and practical importance. The volume is one of the most striking examples of the applications of the methods of scientific investigation to problems of everyday life which has recently appeared, and it appeals to a wide range of interests.

\title{
Angle of Incidence of Short Waves in Radio Reception
}

$I^{N}$ radio reception, a knowledge of the angle of incidence at the ground of short waves returned from the ionosphere is important. The accurate design of antenna arrays for radio communication by the beam system requires information as to the angle of elevation at which the beam is to be projected and of the corresponding angle of arrival.

A paper by Mr. A. F. Wilkins (J. Inst. Elec. Eng., June) describes some experimental measurements, carried out at the Radio Research Station, Slough, of the angle of incidence at the ground of short waves from some American radio-telephone transmitting stations. The angles of incidence were determined from the phase differences of the E.M.F.'s which the arriving waves induced in two similar horizontal aerials at the same height above the ground. To achieve this, the aerials were connected by transmission lines to two similar receivers the outputs from which gave a trace on the fluorescent screen of a cathode ray oscillograph. If the two aerial E.M.F.'s were in phase, a straight line at $45^{\circ}$ to the oscillograph axes would be produced on the screen. When the E.M.F.'s are equal in amplitude but are not in phase, the trace on the oscillograph screen will be an ellipse with its major axis lying along the $45^{\circ}$ line. The phase difference is then the angle subtended by the minor axis at the end of the major axis of this ellipse.

The aerial system at Slough was set up particularly for observations on the signals from several stations at Lawrenceville, New York, on wave-lengths of about 20 metres. The results obtained show that, over the period January-April 1933, one main ray accompanied by other rays of smaller amplitude was received during the normal working period of these stations. The average angle of incidence of this main ray was $72^{\circ}$ measured from the normal to the ground. During the above period this angle remained fairly constant and the oscillograph traces were similar from day to day. Towards the end of April, how. ever, a marked change in the diurnal variation both of angle of incidence and of signal intensity became apparent. At the commencement of transmission, about noon G.M.T., the angle of incidence was about the value given above; but this angle was found to increase gradually until values of $80^{\circ}-90^{\circ}$ were obtained towards sunset. A decrease in the average signal intensity was also noticed during the same period.

These changes are explained as being due to the increased absorption during the summer months, consequent on the greater density of ionisation in the $E$ region of the ionosphere, through which the waves have to travel before and after their reflection at the $F$ region. The rise in angle of incidence exhibited during the evening at Slough is a result of the diminution of the absorption in the $E$ region as the ions start to recombine. This investigation is being continued on a systematic basis with the aid of special pulse transmission from the American stations. 